\title{
Challenges of caring for homeless patients with rheumatic and musculoskeletal disorders in Los Angeles
}

\author{
Richard Seto $^{1,2,3} \cdot$ Kristen Mathias $^{4} \cdot$ Nicole Zagelbaum Ward ${ }^{1,2} \cdot$ Richard S. Panush $^{1,2}$ (i) \\ Received: 21 September 2020 / Revised: 22 October 2020 / Accepted: 8 November 2020 / Published online: 16 November 2020 \\ (C) International League of Associations for Rheumatology (ILAR) 2020
}

\begin{abstract}
Homelessness is a public health crisis. Homeless individuals have significantly worse health outcomes than the general population. We have begun examining challenges of caring for homeless patients with rheumatic and musculoskeletal diseases. Difficulties include physical environment, food and financial insecurity, access to healthcare, low health literacy, and comorbid mental illness, and substance abuse. Based on known prevalences of rheumatic and musculoskeletal diseases (RMSDs), we extrapolate that there are thousands of homeless with rheumatoid arthritis (RA), systemic lupus erythematosus, psoriatic arthritis, gout, and osteoarthritis. We present preliminary observations of disparities in the care of homeless patients with RA seen at the Los Angeles County Medical Center of the Keck School of Medicine of the University of Southern California. They tended to be African American males, missed appointments, utilized emergency services frequently, tended not to be on medications, and exhibited severe disease. We reviewed the available literature on homelessness and homeless healthcare to consider what further studies might be helpful and what interventions might improve the care of patients with RMSDs. We identified several aspirational and practical recommendations. These include ensuring access to healthcare for the homeless (indeed for all); reducing disparities through policy, tailored care, and enhanced social services; and recognizing and treating disease early. Developing better approaches for the care of these homeless has obvious and important implications for other underserved populations needing rheumatologic care, patients with early arthritis, or situations where rheumatologists are unavailable. We believe that physicians have a special responsibility to mitigate inequities in this particularly disadvantaged population.
\end{abstract}

Keywords Homeless $\cdot$ Musculoskeletal disorders $\cdot$ Rheumatic disease $\cdot$ Rheumatoid arthritis $\cdot$ Underinsured $\cdot$ Uninsured

Approved by the University of Southern California Institutional Review Board ("Clinical Course Of Homeless Rheumatic Disease Patients", protocol HS-19-00125 and subsequent amendment HS-19-00125AM001)

Richard S. Panush

panush@usc.edu

1 Division of Rheumatology, Department of Medicine, Keck School of Medicine, University of Southern California, and Los Angeles County, Los Angeles, CA, USA

2 University of Southern California (LAC+USC) Medical Center, Los Angeles, CA, USA

3 Division of Rheumatology, Department of Medicine, UCLA Medical Center, Los Angeles, CA, USA

4 Department of Medicine, University of Chicago Medical Center, Chicago, IL, USA

\section{Patient vignette. A homeless man with uncontrolled rheumatoid arthritis}

Mr. C was an African American man in his early 60s who presented to the rheumatology clinic at the Los Angeles County Medical Center. He was born in Detroit and grew up loving the city's cars and sports teams. He was thoughtful and articulate. He was also homeless.

Mr. C was in a wheelchair, debilitated from his rheumatoid arthritis (RA). He had severe active large and small joint polyarthritis with unrelenting pain and inability to carry out even the simplest of tasks. The diagnosis of RA had been established several years earlier, but he had run out of medications. He missed clinic appointments, as travel was impossibly difficult for him. We could only try to imagine his life as a homeless man with such a severe and chronic illness.

We hospitalized Mr. C. He received intravenous steroids and parenteral methotrexate to begin to try to control his RA. We provided him physical therapy to help him regain strength 
and occupational therapy to help with his activities and selfcare. He was functionally transformed. But continuing to care for this man would be daunting. It was unclear whether we would even see him again [1].

\section{Homelessness}

Homelessness, to most of us who have not had personal or professional experience with it, is probably underrecognized and underappreciated as a serious medical problem. Indeed, it is considered a public health crisis in the USA. Over 560,000 individuals in the USA are estimated to experience homelessness each night [2]. This number is thought to surpass 1 billion globally [3].

It is well established that disparities in health outcomes are irrevocable consequences of socioeconomic factors. These circumstances are collectively known as "social determinants of health" [4]. Homelessness is one such that itself confers a dismal prognosis to the health of affected individual. Homeless individuals have a higher morbidity and mortality and use emergency rooms and hospitals more frequently than their nonhomeless counterparts. In the USA, the average life expectancy for homeless individuals has been estimated to be between 42 and 52 years of age [5], representing a disparity of greater than 35 years when compared with the country's general population [6]. Homeless individuals with chronic diseases are particularly disadvantaged, as they often lack the means to receive regular follow-up care and thus develop preventable complications of longstanding, untreated illness [7, 8].

As physicians, we have a moral responsibility to promote social justice and to eliminate healthcare disparities. This obligation is summarized eloquently by Donald Berwick, who wrote that "Healers are called to heal. When the fabric of communities upon which health depends is torn, then healers are called to mend it [9]." Physicians have an imperative to confront and change the structures and systems that perpetuate inequities in healthcare. Doing so is difficult.

We briefly explore challenges of caring for homeless patients with rheumatic and musculoskeletal disorders. We will present some preliminary observations of disparities in the care of homeless patients with RA who were seen at the Los Angeles County Medical Center. And we will consider what additional studies might be helpful and what interventions might improve the care of these patients. Developing better approaches for the homeless with rheumatic and musculoskeletal disorders would have implications for other populations (unserved or underserved, early arthritis, or situations where rheumatologists are unavailable) needing rheumatologic care.

\section{Rheumatic and musculoskeletal disease in the homeless: what we know}

Appropriately addressing rheumatic and musculoskeletal disease in the homeless community is a complex undertaking with a multitude of barriers. We are aware of only scant data about arthritis and musculoskeletal disease in the homeless community. This likely reflects the barriers to obtaining access to doctors, appropriate diagnostics and care faced by the homeless, and inability of current healthcare systems to identify, follow, track, and manage these patients over time.

Homeless patients are more at risk for poorer healthcare outcomes than their counterparts. This is the result of longstanding inequalities in multiple realms - including physical environment (poor hygiene), social support networks (access to healthcare, dental care, transportation), economic environment (poor nutrition, lower rate of employment), individual risk factors (lower education and health literacy level), housing security (higher exposure to communicable illness), and lifestyle and behavior (higher rate of substance abuse, tobacco use, mental illness) [5]. We presume that these issues are similarly relevant in homeless individuals with rheumatic and musculoskeletal disease (Table 1).

\section{Rheumatic diseases}

We are unaware of large-scale cross-sectional data about homeless patients and rheumatic disease and, therefore, we can only estimate prevalence. The prevalence of RA has been between 0.5 and $1 \%$ of the general population [10]. Thus, among the 560,000 homeless individuals in the USA [2], there should be at least 2800 homeless with RA.

The incidence of systemic lupus erythematosus (SLE) is increasing. Specifically, there is an increase in mortality among ethnic minorities with higher poverty rates, which include the homeless community. The prevalence of SLE has been estimated to be between 14.6 and 122 per 100,000. Psoriatic arthritis (PsA) has a prevalence of 1 per 1000 individuals. Polymyalgia rheumatica (PMR) has a prevalence rate around 6 cases per 1000 individuals. Based on the aforementioned estimate of homelessness in the USA, there should be at least 3920 homeless with these diseases (Table 1). Although these diseases occur in a minority of patients, they represent a significant disease burden with implications for quality of life and even life expectancy if left chronic and uncontrolled [11]. The incidence of gout among the homeless was found to be $6 \%$ in a survey of 299 homeless individuals who lived across two homeless shelters in San Francisco, CA [5] (Table 1). Each of these chronic conditions has an increased incidence among elderly patients, and treatment often requires strict medication compliance, often with multiple medications, for 
Table 1 Rheumatic and musculoskeletal disease in the homeless: summary information

Estimated number of homeless in the USA

Estimated number of homeless globally

Estimated life expectancy of homeless in the USA

Estimated life expectancy of non-homeless in the USA

Barriers to care for homeless

Estimated number of homeless with RA in the USA

Estimated number of homeless with lupus, psoriatic arthritis, and polymyalgia rheumatica in the USA

Estimated incidence of gout in homeless in the USA

Lifetime risk for knee OA in homeless in the USA

Greater than 560,000
Greater than 1,000,000,000
Between 42 and 52 years
79 years
Physical environment, access to healthcare and education,
$\quad$ food and transportation insecurity, lifestyle and behavior,
$\quad$ comorbid medical and mental illness
2800
3920
$6 \%$
$44.7 \%$

optimal outcomes. The homeless community with rheumatic diseases is at increased risk for poor outcomes.

\section{Musculoskeletal diseases}

Here too we are unaware of studies on the prevalence or management of musculoskeletal disease in the homeless community. Lifetime risk for symptomatic knee osteoarthritis (OA) in the general population has been reported to be $44.7 \%$ with risk factors including increased age, female sex, and obesity [10] (Table 1). Several cross-sectional studies exist which estimated joint pain and self-reported history of arthritis among the homeless population. One cross-sectional study of 312 homeless participants in Toronto shelters found over half of respondents to have chronic pain and over $30 \%$ of respondents to have a self-reported history of arthritis [12]. In another crosssectional, population-based study of 350 homeless patients greater than age 50 years, $44.3 \%$ reported a history of "arthritis" which was strongly associated with chronic pain (adjusted odds ratio 4.6, $p<0.001$ ) [13]. A study of 145 homeless individuals at a day shelter were interviewed using the short form 12-item survey (SF-12) as a brief health assessment tool and found that $48 \%$ of participants experienced joint pain in the past 12 months but only $20 \%$ reported a history of being diagnosed with arthritis [13]. Of note the type of arthritis was not specified and further indicates the obstacles to obtaining appropriate diagnosis and treatment in homeless patients.

\section{Preliminary observations of homeless patients with RA}

Our medical center and associated facilities have the privilege of providing care to the uninsured in Los Angeles County, including approximately 66,400 homeless individuals, among whom should be an estimated 332 to 664 with RA as well as additional patients with other rheumatologic and musculoskeletal disorders [14-16]. As noted, the unique needs of homeless RA patients are not known, and there is a paucity of data about homeless patients with rheumatic and musculoskeletal disorders. We therefore sought to identify and describe homeless patients with RA in order to understand their clinical course, outcomes, hardships, and unique barriers to care so that we could begin to develop better approaches to address their particular needs. We hypothesized that homeless patients with RA fared less well than their non-homeless counterparts.

Homeless patients were found by reviewing charts from RA clinics and by filtering by diagnoses of RA. Homelessness was determined by patients confirming living on the streets, in a tent, or in a homeless shelter. In this study, data were obtained from the medical records. Controls of matching ethnicity were then identified. We noted demographic information, clinical course, percentage of appointments to rheumatology and primary care clinics attended, visits to the Emergency Department (ED) and our Urgent Care facility, and medications. We assessed disease status, erythrocyte sedimentation rate (ESR), and C-reactive protein (CRP) (average of last 3 values), rheumatoid factor (RF), anticyclic citrullinated peptide (anti-CCP), and the physician's judgment of controlled vs uncontrolled disease as stated in the medical records. We were not able to use the rheumatologically accepted outcome assessments, as these were not consistently recorded in charts by the various residents, fellows, and other physicians evaluating these patients over the years. In the context of this study, patients were considered to have controlled disease if inflammatory markers were trending down or were at low levels, and physical exam in the medical records suggested improved joint pain/synovitis. Patients were considered to have uncontrolled disease when patients had continued symptomatic disease as well as elevated or rising inflammatory markers. Data were analyzed with unpaired $t$ test for datasets to obtain $t$ and 
$p$ values and Fisher's exact test, two-tailed, to analyze categorical variables, i.e., controlled vs uncontrolled disease. This study received IRB approval March 2019, protocol HS-1900125, and subsequent amendment HS-19-00125-AM001. This study took place from March 2019 to June 2020, evaluating charts of all relevant subjects from December 2014 to June 2020.

We identified 17 homeless $(\mathrm{H})$ and 17 non-homeless $(\mathrm{NH})$, control patients with RA. Their clinical features are presented in Table 2. Homeless were $54 \pm 2$ (mean \pm SEM) years old, non-homeless patients $60 \pm 2$; homeless $47 \%$ male and $53 \%$ female, non-homeless $12 \%$ male and $88 \%$ female; homeless 41\% African American, 41\% Latin American, 12\% Caucasian, and $6 \%$ other, while non-homeless were $41 \%$ African American, 35\% Latin American, 6\% Caucasian, and $18 \%$ other; disease duration for homeless was $12 \pm 2$ years and non-homeless $15 \pm 3$ years $(t=0.75, p=0.459)$; and erosive disease, $63 \%$ homeless vs $65 \%$ non-homeless $(p=1)$. Statistically significant differences between the populations included overall appointments kept, $57 \%$ homeless vs $82 \%$ non-homeless $(p<0.0001)$; rheumatology appointments kept, $50 \%$ homeless vs $89 \%$ non-homeless $(p<0.0001)$; primary care appointments kept, $56 \%$ homeless vs $79 \%$ non-homeless ( $p=0.012) ; \mathrm{ED} /$ Urgent Care visits, $10 \pm 12$ homeless vs $2 \pm 2$ non-homeless $(p=0.014)$; using anti-rheumatic medication(s), $71 \%$ homeless vs $100 \%$ non-homeless ( $p=0.045$ ); and uncontrolled disease, $70.6 \%$ homeless vs $17.6 \%$ nonhomeless $(p=0.005)$. ESR $(43 \pm 8 \mathrm{~mm} / \mathrm{h})$ and CRP $(34 \pm$ $12 \mathrm{mg} / \mathrm{L})$ were higher in the homeless than non-homeless (ESR $22 \pm 4 \mathrm{~mm} / \mathrm{h}, \mathrm{CRP} 13 \pm 8 \mathrm{mg} / \mathrm{L}$ ) but not (quite) statistically significantly different. In the homeless group, rheumatoid factor was $144 \pm 161 \mathrm{iU} / \mathrm{ml}$ and anti-CCP $292 \pm 123 \mathrm{U} / \mathrm{ml}$ and $282 \pm 123 \mathrm{iU} / \mathrm{ml}$ and $213 \pm 31 \mathrm{U} / \mathrm{ml}$ in the non-homeless (Table 2).

Medications of patients were categorized into diseasemodifying anti-rheumatic drugs (DMARDs), biologic DMARDs, and corticosteroids. As exhibited in Table 2, 59\% percent of homeless vs 95\% non-homeless were on DMARDs $(p=0.039), 53 \%$ homeless and non-homeless were on biologic DMARDs $(p=1)$, and $47 \%$ of the homeless patients were on
Table 2 Clinical features of homeless and non-homeless patients with RA

\begin{tabular}{|c|c|c|c|}
\hline Characteristic & $\begin{array}{l}\text { Homeless } \\
(n=17) \\
(\text { mean } \pm \mathrm{S}\end{array}$ & $\begin{array}{l}\text { Not homeless (control) } \\
(n=17) \\
\text { percentage }\end{array}$ & Comparisons \\
\hline Age (years) & $54 \pm 2$ & $60 \pm 2$ & \\
\hline Percentage male & $47 \%$ & $12 \%$ & $p=0.057$ \\
\hline African American & $41 \%$ & $41 \%$ & \\
\hline Latin American & $41 \%$ & $35 \%$ & \\
\hline Caucasian & $12 \%$ & $6 \%$ & \\
\hline Other & $6 \%$ & $18 \%$ & \\
\hline Duration of disease (years) & $12 \pm 2$ & $15 \pm 3$ & $t=0.75, p=0.459$ \\
\hline Overall appts ${ }^{1}$ kept $(\%)$ & $57 \%$ & $82 \%$ & $t=4.47 p<0.0001$ \\
\hline Rheum appts ${ }^{1}$ kept (\%) & $50 \%$ & $89 \%$ & $t=4.99, p<0.0001$ \\
\hline Primary care appts ${ }^{1}$ kept (\%) & $56 \%$ & $79 \%$ & $t=2.68, p=0.012$ \\
\hline ED/urgent care visits (no.) & $10 \pm 12$ & $2 \pm 2$ & $t=2.59, p=0.014$ \\
\hline On RA medications $^{2,3}(\%)$ & $71 \%$ & $100 \%$ & $p=0.045$ \\
\hline Uncontrolled disease $^{4}(\%)$ & $70.6 \%$ & $17.6 \%$ & $p=0.005$ \\
\hline Erosive disease & $63 \%$ & $65 \%$ & $p=1$ \\
\hline $\mathrm{RF}(\mathrm{IU} / \mathrm{mL})$ & $144 \pm 61$ & $282 \pm 123$ & $t=1.04, p=0.311$ \\
\hline Anti-CCP (U/mL) & $187 \pm 42$ & $210 \pm 31$ & $t=0.46, p=0.651$ \\
\hline $\operatorname{ESR}(\mathrm{mm} / \mathrm{h})$ & $43 \pm 8$ & $26 \pm 4$ & $t=1.94, p=0.062$ \\
\hline CRP (mg/L) & $34 \pm 12$ & $13 \pm 8$ & $t=1.55, p=0.132$ \\
\hline DMARDs & $59 \%$ & $94 \%$ & $p=0.039$ \\
\hline Biologic DMARDs & $53 \%$ & $53 \%$ & $p=1$ \\
\hline Corticosteroids & $47 \%$ & 0 & $p=0.003$ \\
\hline
\end{tabular}

\footnotetext{
1 "Appts," appointments

${ }^{2}$ Currently on DMARDs (disease modifying anti-rheumatic drugs), biologics, and/or infusions

${ }^{3}$ Three homeless patients had RA medications intentionally withheld due to HIV-related issues, while another two were not cared for in our RA clinic

${ }^{4}$ Uncontrolled disease defined as continued symptomatic disease as well as elevated/rising inflammatory markers
} 
corticosteroids vs none of the non-homeless ( $p=0.003)$. All rheumatological medications, including steroids, were prescribed by our rheumatology clinic physicians. It could not be ascertained whether patients were indeed taking their prescribed medications.

Three of our homeless RA patients experienced qualitative clinical improvement upon obtaining stable housing.

These preliminary data confirmed the anticipated conclusion that homeless patients exhibited worse compliance with medications and clinic appointments, higher use of emergency services, and poorer disease control than their non-homeless counterparts. Examination of the medications of both cohorts showed one notable difference- $47 \%$ of homeless patients were on oral corticosteroids, whether a taper or maintenance, while none of non-homeless had a prescription for steroids. Without yet having interviewed the patients, we can only speculate about possible difficulty with compliance with DMARDs/biologics due to multiple doses, refrigeration, access issues, lower volume of medications in people who often have to carry their most valuable belongings with them at all times, relative ease of once daily dosing of steroids, overall poor control of disease requiring steroids, and possible prescriptions of corticosteroids provided at times of emergency and urgent care visits.

It is of interest that a prior study found that removing subsistence difficulties improved health outcomes [17]. Our observations, while small, were similar. Our three homeless RA patients who subsequently obtained housing then experienced notable clinical improvement.

Our observations thus far are limited. The single-center, retrospective design of the study and small sample size in a single population in the USA might not generalize. Furthermore, standard rheumatologic outcome measures were not employed due to the retrospective design and may have been imprecise in attempting to judge disease activity and control. Nevertheless, we believe that these preliminary data represent an important first step in characterizing health disparities for homeless patients with rheumatic and musculoskeletal disorders.

\section{Future directions}

\section{Future studies needed}

We hope that our observations lead to further studies contributing to reducing health disparities among homeless patients with rheumatic and musculoskeletal disease and providing them better care. Additional quantitative and qualitative information is needed.

Quantitatively, studies that track homeless patients and measure disease severity over time will allow providers to understand the unique phenotypes of disease that this population carries. Similarly, data on therapies prescribed-along with efficacy, adverse effects, and adherence pattern-will help establish standards for treatment for this population. Finally, data on compliance with follow-up appointments and rehospitalizations can help subcategorize $\operatorname{risk}(\mathrm{s})$ within the population.

Qualitatively, it would be invaluable to understand homeless patients' perspectives of obstacles to their care and how we, society, and our healthcare systems can address and solve these impediments to care.

\section{Recommendations for care}

We will divide our recommendations for care into those that are aspirational and those that are practical (Table 3 ). Aspirationally, we believe that healthcare is an essential right to all individuals and should be safe, patient-centered, equitable, effective, efficient, timely, responsive, and humanistic $[18,19]$. Ensuring access to care for homeless individuals would directly improve disparities in this population.

Beyond healthcare, we must seek to ameliorate other inequities faced by the homeless that affect the care they receive. A review on caring for the homeless echoes this. In accordance with Maslow's "Hierarchy of Needs," homeless individuals first need access to food and shelter before they can consider their healthcare needs [7]. Patients will be unable to reliably present to a primary care provider when waiting in line for a shelter to sleep that night takes priority. Therefore, when writing new policy and allocating resources for homeless individuals, addressing disparities in housing and food security should be treated as a healthcare priority. In addition to securing housing and food for this population, we should enact policies that improve other disparities faced by the population. As mentioned previously, physical environment, poverty, access to education, and transportation insecurity are some factors that contribute to poorer health outcomes in the homeless. As Berwick wrote, "[T] he rescue of a society and the restoration of a political ethos that remembers to heal have become the physician's jobs, too [20]." Physicians, when able, should work to advance policies that reduce healthcare disparities in this incredibly under-resourced population.

Practically speaking, our thoughts about care in this population derive largely from approaches developed to reach patients with "early arthritis." The concept of identifying, detecting, and treating patients' rheumatic disorders early and aggressively to prevent disease progression and limit eventual disability must also apply to the homeless; we will need imaginative and innovative approaches to reaching them [21]. "Street Medicine" is one such strategy. "Street Medicine" includes the efforts used to provide healthcare to homeless patients who often have transient living situations and whose care requires a multitude of special considerations. Some elements include mobile clinics, extensive collaboration with social services, affiliations with continuity clinics and hospitals, a consistent set of providers who can build 
Table 3 Summary of recommendations for care of homeless patients with rheumatic and musculoskeletal disorders

\begin{tabular}{|c|c|c|}
\hline Issue & Recommendation & $\begin{array}{l}\text { Type of } \\
\text { recommendation }\end{array}$ \\
\hline Access to healthcare & Universal healthcare for all & Aspirational \\
\hline $\begin{array}{l}\text { Disparities in housing, } \\
\text { income, education, } \\
\text { and transportation }\end{array}$ & $\begin{array}{l}\text { Governmental policy and } \\
\text { bolstered social programs } \\
\text { to reduce disparities and } \\
\text { provide equal opportunity } \\
\text { for the homeless }\end{array}$ & Aspirational \\
\hline $\begin{array}{l}\text { Disparities in housing, } \\
\text { income, education, } \\
\text { and transportation }\end{array}$ & $\begin{array}{l}\text { Enhanced social services in } \\
\text { mobile clinics, continuity } \\
\text { clinics, hospitals }\end{array}$ & Practical \\
\hline $\begin{array}{l}\text { Disparities in housing, } \\
\text { income, education, } \\
\text { and transportation }\end{array}$ & $\begin{array}{l}\text { Training and incentivizing } \\
\text { providers to link patients } \\
\text { to resources and to } \\
\text { advocate for policies that } \\
\text { improve disparities }\end{array}$ & Practical \\
\hline $\begin{array}{l}\text { Comorbid mental } \\
\text { illness and substance } \\
\text { abuse }\end{array}$ & $\begin{array}{l}\text { Training providers on } \\
\text { establishing rapport and } \\
\text { addressing common } \\
\text { comorbidities. Mental } \\
\text { health and substance } \\
\text { abuse services integrated } \\
\text { into clinical settings }\end{array}$ & Practical \\
\hline $\begin{array}{l}\text { Disease progression } \\
\text { causing disability }\end{array}$ & $\begin{array}{l}\text { Early arthritis identification } \\
\text { and treatment through } \\
\text { "Street Medicine" and } \\
\text { screening during Primary } \\
\text { Care appointments }\end{array}$ & Practical \\
\hline $\begin{array}{l}\text { Inability to take } \\
\text { medications }\end{array}$ & $\begin{array}{l}\text { Long-acting medications. } \\
\text { Delivery and storage of } \\
\text { medications in shelters }\end{array}$ & Practical \\
\hline $\begin{array}{l}\text { Adherence to clinic } \\
\text { appointments }\end{array}$ & $\begin{array}{l}\text { Involving friends, family, } \\
\text { volunteers, and social } \\
\text { workers to help patient } \\
\text { attend appointments. } \\
\text { Making walk-in } \\
\text { appointments and } \\
\text { rescheduling } \\
\text { appointments easy. } \\
\text { Innovative adaptation, } \\
\text { development of, and } \\
\text { utilization of "Street } \\
\text { Medicine" programs, } \\
\text { subjective outcomes } \\
\text { assessments, } \\
\text { "tele-health," information } \\
\text { technology, care } \\
\text { extenders, and artificial } \\
\text { intelligence to } \\
\text { communicate with and } \\
\text { care for homeless patients }\end{array}$ & Practical \\
\hline
\end{tabular}

rapport with patients, and the use of technology to electronically track health information and disease progression [22]. We believe that incorporating measures like these is essential to improving care for homeless patients with rheumatic and musculoskeletal disease. Disease progression in the homeless would likely lead to increased hospitalizations and morbidity in an already disadvantaged population. Furthermore, many employment options for the homeless rely on the ability to perform manual labor. Avoiding disability would thus give homeless individuals a better chance to achieve subsistence [23]. For this reason, we strongly recommend that providers screen homeless patients for rheumatic and musculoskeletal disorders during primary care appointments.

In addition to detecting and treating disease in this population early, we believe that providers who interact with homeless patients frequently should be well equipped to connect these individuals to local resources for housing, food, and medical care. In the future, clinicians may benefit from the development of a specialty track in the care of homeless patients in order to better care for patients who have cooccurring interactions between physical health, mental health, and substance abuse. It is important for providers to establish long-lasting relationships with homeless patients to establish a therapeutic alliance that can surmount barriers to compliance such as mistrust of the medical system, mental health comorbidities, and the stigma of homelessness [24]. Allocating special funding to support physicians who pursue special training in care of the homeless would serve as an additional way to incentivize this greatly needed role.

Finally, we offer specific recommendations for care based on management of other chronic diseases in the homeless [25-27]. Medication adherence can be made more feasible through the use of long-acting medications, delivery of medications directly to shelters, and designated areas within shelters for medication storage. Adherence to appointments can be encouraged by involving social workers in patients' care early and, when possible, getting friends, family, or volunteers to bring patients to appointments [25]. Homeless veterans were found to have a $19 \%$ reduction in emergency department use and a $34.7 \%$ reduction in hospitalizations when they received care through homeless medical homes that addressed social determinants of health through measures such as providing hygiene products, transportation, food, and clothing [26]. Lastly, a study about primary care experiences among homeless individuals in primary care clinics of the Veteran's Administration suggested that tailoring care to someone's homelessness through measures such as integrated mental health services, dedicated social support staff, and emphasizing walk-in availability may make primary care experiences more positive for this population [27]. All of these measures could be successfully adapted and extended to care of homeless individuals with rheumatic and musculoskeletal disease.

\section{Patient vignette revisited. A non-homeless man with controlled RA}

Twenty months after his initial diagnosis and hospitalization, Mr. C presented again to our rheumatology clinic. He and his 
wife were living comfortably in public housing. He was no longer using a wheelchair but rather was ambulating with a cane. He was being followed by another Los Angeles county clinic, had reliable access to treatment, and was on his antirheumatic medications (methotrexate, sulfasalazine, and hydroxychloroquine). His disease was relatively quiescent. As Mr. C walked to the attending physician who initially saw him almost 2 years earlier, both experienced a deep sense of satisfaction that, against expectations and despite all of confounding factors auguring a poor outcome, in this instance we had triumphed (1).

\section{Concluding remarks}

Health disparities in the homeless are a complex and challenging problem; there is no single solution that will resolve the issue. The homeless population is a heterogenous group of individuals with multiple reasons for being homeless, including economic hardship, weakened social network, disabling health condition, mental illness, and victimization from violence [28]. Our homeless population with rheumatic and musculoskeletal disease likely has similarly diverse causes for their homelessness. Helping as many of them as possible will require an innovative, large, multi-disciplinary approach. The emergence of "Street Medicine" is a large first step in this endeavor. It is our hope that our observations might serve as a start in developing approaches to better reach and deliver care to this group of patients. Such efforts and approaches for the homeless with rheumatic and musculoskeletal disorders would also have important implications for other populations needing rheumatologic care.

At present, the coronavirus pandemic has placed a disproportionate burden of disease on the most vulnerable and marginalized members of society. We hope the medical community can emerge from the pandemic with renewed commitment to social justice [29]. We can and must do better for this group of particularly disadvantaged patients.

Authors' contribution All authors contributed to this work.

\section{Compliance with ethical standards}

We complied with all institutional and review board requirements. This was approved by the University of Southern California Institutional Review Board ("Clinical Course of Homeless Rheumatic Disease Patients," protocol HS-19-00125 and subsequent amendment HS-1900125-AM001) as indicated in the manuscript.

\section{Disclosures None.}

Consent for publication If this is accepted for publication, we assign copyright to the publisher.

\section{References}

1. Tran H, Panush RS (2018) Some days you win. Clin Rheumatol 37: 2565-2569. https://doi.org/10.1007/s10067-018-4223-y

2. Henry M, Watt R, Mahathey A, Ouellette J, Sitler A (2019) The 2019 Annual Homeless Assessment Report (AHAR) to Congress. https://files.hudexchange.info/resources/documents/2019-AHARPart-1.pdf. Accessed 8 August 2020

3. Speak S (2019) The state of homelessness in developing countries. https://www.un.org/development/desa/dspd/wpcontent/uploads/ sites/22/2019/05/SPEAK_Suzanne_Paper.pdf

4. Braveman P, Gottlieb L (2014) The social determinants of health: it's time to consider the causes of the causes. Public Health Rep 129:19-31. https://doi.org/10.1177/00333549141291S206

5. Maness DL, Khan M (2014) Care of the homeless: an overview. Am Fam Physician 89:634-640

6. Arias E (2019) United States life tables, 2017. Natl Vital Stat Rep 68(7):1-66

7. Davies A, Wood LJ (2018) Homeless health care: meeting the challenges of providing primary care. Med J Aust 209(5):230-234

8. Stafford A, Wood L (2017) Tackling health disparities for people who are homeless? Start with social determinants. Int J Environ Res Public Health 14(12):1535. https://doi.org/10.3390/ ijerph14121535

9. Berwick DM (2020) The moral determinants of health. JAMA 324(3):225-226. https://doi.org/10.1001/jama.2020.11129

10. Gabriel SE, Michaud K (2009) Epidemiological studies in incidence, prevalence, mortality, and comorbidity of the rheumatic diseases. Arthritis Res Ther 11(3):229. https://doi.org/10.1186/ar2669

11. Hwang SW, Wilkins E, Chambers C, Estrabillo E, Berends J, MacDonald A (2011) Chronic pain among homeless persons: characteristics, treatment, and barriers to management. BMC Fam Pract 12:73. https://doi.org/10.1186/1471-2296-12-73

12. Landefeld JC, Miaskowski C, Tieu L, Ponath C, Lee CT, Guzman D, Kushel M (2017) Characteristics and factors associated with pain in older homeless individuals: results from the HOPE HOME study. J Pain 18(9):1036-1045. https://doi.org/10.1016/j.jpain.2017.03. 011

13. Larson CO (2002) Use of the SF-12 instrument for measuring the health of homeless persons. Health Serv Res 37(3):733-750. https://doi.org/10.1111/1475-6773.00046

14. (2020) 2020 Greater Los Angeles Homeless Count. Los Angeles Homeless Services Authority. https://www.lahsa.org/documents? $\mathrm{id}=4558$-2020 -greater-los-angeles-homeless-count-presentation. pdf. Accessed June 27, 2020

15. Myasoedova E, Crowson CS, Kremers HM, Therneau TM, Gabriel SE (2011) Is the incidence of rheumatoid arthritis rising? Results from Olmsted County, Minnesota, 1955-2007. Arthritis Rheum 62(6):1576-1582. https://doi.org/10.1002/art.27425

16. Hunter TM, Boytsov NN, Zhang X, Schroeder K, Michaud K, Araujo AB (2017) Prevalence of rheumatoid arthritis in the United States adult population in healthcare claims databases, 2004-2014. Rheumatol Int 37(9):1551-1557. https://doi.org/10. 1007/s00296-017-3726-1

17. Gelberg L, Gallagher TC, Andersen RM, Koegel P (1997) Competing priorities as a barrier to medical care among homeless adults in Los Angeles. Am J Public Health 87(2):217-220. https:// doi.org/10.2105/AJPH.87.2.217

18. Institute of Medicine (US) Committee on Quality of Health Care in America (2001) Crossing the Quality Chasm: a new health system for the 21st Century. National Academies Press (US), Washington (DC)

19. Panush RS (2011) Rheum with a view. Why I sometimes read poetry instead of medicine-and why you should too. Rheumatologist 5(11):47-49 
20. Berwick DM (2017) Moral choices for today's physician. JAMA 318(21):2081-2082. https://doi.org/10.1001/jama.2017.16254

21. Kovacs D, Torralba KD, Fox DA, Solomon DH, Panush RS (2012) Reflecting on early arthritis. J Rheumatol 39(11):2059-2061. https://doi.org/10.3899/jrheum.121030

22. Howe EC, Buck DS, Withers J (2009) Delivering health care on the streets: challenges and opportunities for quality management. Qual Manag Health Care 18(4):239-246. https://doi.org/10.1097/QMH. 0b013e3181bee2d9

23. (2002) Dealing with Disability: Physical Impairments \& Homelessness. HCH Clinicians' Network. https://nhchc.org/wpcontent/uploads/2019/08/hh.10_02.pdf. Accessed August 5, 2020

24. Hicks A, Minor J, Chetta M, Kadio B (2020) Rheumatic diseases in aged homeless in US and Canada. Arch Rheum Arthritis Res 1(2): 1-7 ARAR.MS.ID.000510

25. Podymow T, Turnbull J (2013) Management of chronic kidney disease and dialysis in homeless persons. Kidney Int Suppl 3(2): 230-235. https://doi.org/10.1038/kisup.2013.21

26. O'Toole T, Johnson EE, Aiello R, Kane V, Pape L (2016) Tailoring care to vulnerable populations by incorporating social determinants of health: the Veterans Health Administration's "Homeless Patient
Aligned Care Team" Program. Prev Chronic Dis 13:E44. https:// doi.org/10.5888/pcd13.150567

27. Chrystal JG, Glover DL, Young AS, Whelan F, Austin EL, Johnso NK, Pollio DE, Holt CL, Stringfellow E, Gordon AJ, Kim TA, Daigl SG, Steward L, Kertesz G (2015) Experience of primary care among homeless individuals with mental health conditions. PLoS One 10(2):e0117395. https://doi.org/10.1371/journal.pone. 0117395

28. (2019) 2019 homeless count by city of Los Angeles Council District (CD). Los Angeles Homeless Services Authority. https:// www.lahsa.org/data?id=12-count-by-city-council-district. Accessed June 5, 2020

29. Feldman CH, Ramsey-Goldman R (2020, 2020) Widening disparities among patients with rheumatic diseases in the COVID-19 era: an urgent call to action. Arthritis Rheum. https://doi.org/10.1002/ art.41306 Online ahead of print

Publisher's note Springer Nature remains neutral with regard to jurisdictional claims in published maps and institutional affiliations. 